\title{
DANIEL LINK Y LA CLASE: PROBLEMAS DE CONVIVENCIA
}

\author{
Mariana Catalin \\ Centro de Estudios en Literatura Argentina \\ Universidad Nacional de Rosario, Argentina \\ marianacatalin@gmail.com
}

\begin{abstract}
RESUMEN / ABSTRACT
El presente trabajo busca realizar un acercamiento a los modos de la producción ensayística de Daniel Link a partir de un interrogante que cruza toda su producción: la pregunta por cómo vivir juntos. Para esto, en una primera instancia, se realiza un análisis de la aparición explícita del interrogante en una serie de textos del blog del autor (linkillo.blogspot.com), para observar qué problemas se condensan en torno al mismo. A partir de este contexto, en un segundo momento, se abre un recorrido por dos de sus más recientes libros de ensayos, Clases. Literatura y disidencia (2005) y Fantasmas. Imaginación y sociedad (2009). Allí, además de los usos que se articulan a partir de su aparición explícita, el interrogante permite pensar la relación entre clasificación y cualificación, dos conceptos centrales en la producción de Link.

Palabras ClaVe: ensayo, comunidad, clase, cualificación, Daniel Link.

This paper approaches Daniel Link's essays taking as a departure point a question ever present in his production: how to live together. The first part focuses on the explicit reference of the question and the issues it raises in a series of texts from the author's blog (linkillo.blogspot. com). The second part deals with two of his essay books, Clases. Literatura y disidencia (2005) and Fantasmas. Imaginación y sociedad (2009). The approach to the central question in these works allows for the relationship between classification and qualification, two central concepts in Link's production.
\end{abstract}

KEYWORDS: essay, community, class, qualification, Daniel Link. 
(...) la paradoja, la contradicción, la aporía de una puesta en común de las distancias.

Roland Barthes, Cómo vivir juntos

La mirada de Daniel Link es, tal vez, una de las más abarcadoras del ensayo argentino actual. Desde el comienzo de su producción, marcado por el libro $L a$ chancha con cadenas (1994) pero también por el armado de dos compilaciones que tomaban como eje respectivamente el policial y la ciencia ficción (El juego de los cautos (1992) y Escalera al cielo. Utopía y ciencia ficción (1994)), los objetos que han ocupado su reflexión han sido múltiples y diversos. La apertura de su blog en el 2003 (linkillo.blogspot.com) acentuó estos intentos iniciales: las críticas y opiniones sobre arte y literatura se conjugan allí con la reflexión sobre el medio que las congrega (internet), el interés por productos y estrellas de los mass media, el análisis de episodios y personajes de la vida política nacional e internacional, la narración de anécdotas autobiográficas y el desarrollo de fragmentos que tal vez podrían calificarse como "ficciones".

En este contexto radicalmente heterogéneo, hay un interrogante que insiste, fundamentalmente en sus textos de intervención: ¿cómo vivir juntos? Los productos que permiten rondar los problemas a él asociados (las comunidades y las "formas de (la) vida") atraen casi necesariamente el interés del ensayista. El mismo se constituye como una herramienta fundamental para el abordaje de las producciones de uno de sus autores fetiche, Manuel Puig: "El beso es obviamente Las mil y una noches, donde cada historia vale por un día más, y donde cada día sirve para la interrogación sobre formas de vida (sobre cómo vivir juntos en un universo que postula toda separación como necesaria y toda comunidad como insostenible)." ("La obra como exigencia" s/p). Pero también se erige como un eje central para el análisis de Lost, una de las series que más ha capturado la atención de Link en el último tiempo:

“¿Cómo vivir juntos?" la pregunta que resuena en los capítulos de Lost (...) es correlativa a otra, “¿cómo y para qué reproducirse?", que son las preguntas de nuestra época. No es que Lost pretenda dignidad filosófica alguna (...) Todo lo que puede leerse en Lost (...) nos viene dado como por añadidura, sin el impulso balzaciano o wagneriano hacia la totalización tan propios del s. XIX y sin la vocación destructiva de la totalidad (paródica) tan característica del siglo XX (Textos de ocasión 268). 
Sin duda, el cuestionamiento cifra un interés biopolítico y es uno de los ejes desde donde se define el "dispositivo ético" del ensayista. Ahora bien, al mismo tiempo y pervirtiendo un poco su objetivo explícito, la insistencia del interrogante propicia la aparición de una serie de preguntas en torno a la multiplicidad de objetos que conviven en la escritura del autor y, desde ahí, habilita la posibilidad de arriesgar algunas hipótesis sobre los modos de sus ensayos. No solo sobre el eclecticismo que los caracteriza, que de por sí no vuelve necesaria la interpelación; sino, fundamentalmente, sobre los modos de relación entre lo que el ensayista propone como imperativos para el abordaje y los objetos a los que los aplica y sobre la forma en que dichos imperativos se relacionan entre sí y con sus intereses. ¿Cómo viven juntos el rechazo constante de la "clase" - precepto teórico fundamental para el autorcon la simultánea necesidad de cualificación que se plantea en sus ensayos y la posibilidad de que dicha necesidad se convierta en una axiología? ${ }^{1}$ ¿Qué lugar ocupa, en el contexto de este rechazo, el interés por los géneros literarios, productos fuertemente clasificatorios? ¿Y la persistencia en el análisis de ciertas series televisivas que desborda cualquier acercamiento desde una perspectiva sociológica? Si Link repite su atracción por aquellos escritores que plantean en su literatura "una tensión incómoda entre arte y cultura industrial" (Leyenda 152), tensión que podría permitir arriesgar un modo de convivencia entre imperativos e intereses, ¿puede dicha incomodidad convertirse en un valor al que se apela fácilmente y, por lo tanto, en una nueva grilla clasificatoria? Sabemos, porque el autor nos lo explicita en Fantasmas. Imaginación y sociedad (2009), que "clases y atributos (clasificación y cualificación) bailan la misma ronda tomados de la mano" (9). Ahora bien, ¿cuáles son los movimientos a que dicho baile obliga?

Alan Pauls sostiene, en el prólogo que escribe a Cómo vivir juntos: simulaciones novelescas de algunos espacios cotidianos de Roland Barthes (uno de los referentes casi obvios del uso que hace Link), que la puesta en el centro de dicha pregunta supuso en la producción del autor francés un pasaje de la atopía como valor a la utopía. Un pasaje que pareció volverse necesario debido a la degradación del intento constante de salir de todo encasillamiento:

Sobre la insistencia de Link en "la potencia culturalmente indomesticable del arte" y su intento constante de escape a las normalizaciones, cf. Gasparri, "Las aventuras (in)formales de Linkillo". 
El problema de la atopía, como el de todo valor barthesiano, es un problema orgánico: se degrada. Nacido de una voluntad compulsiva de diferenciación, suerte de desvío o desaire gozoso, tiene un primer momento exaltado (...) Pero una vez que se aparta del paradigma que ha burlado, a medida que se aleja y cobra autonomía y respira, soberano, en la órbita que ha creado, ese valor nuevo parece temblar y desconcertarse (...) como si descubriera que sus posibilidades de vida son proporcionales al grado de proximidad que mantiene con el paradigma que se proponía desbaratar (Cómo vivir juntos 13)

Es el paso, entonces, no a otro valor sino a una dimensión otra de la reflexión, que se constituye a través de la utopía y que se condensa en uno de sus momentos en torno al interrogante por cómo vivir juntos, el que abre en la producción del autor francés las puertas a la imaginación, a la posibilidad de "Soñar en voz alta una investigación" (Cómo vivir juntos 14).

En este contexto, me propongo realizar, en un primer momento, un análisis de la aparición explícita de la pregunta en una serie de textos del blog de Link, para observar los problemas que nuclea. Y, a partir de allí, abrir un recorrido por dos de sus más recientes libros de ensayos, Clases. Literatura y disidencia (2005) y Fantasmas. Imaginación y sociedad, con el fin de observar no solo las menciones explícitas del interrogante sino también las posibilidades que éste abre, al generarlo como punto de vista, para pensar la relación entre clases y cualificaciones como un verdadero problema que le exige al autor imaginar formas para ensayar modos de convivencia.

\section{I.- UMBRALES}

La pregunta por cómo vivir juntos y su puesta en el centro de las posibilidades de una comunidad es, en primera instancia, uno de los instrumentos predilectos del ensayista para desatar la reflexión en torno a las relaciones entre arte y política. Esto se explicita claramente en el análisis que, a propósito de la $29^{a}$ Bienal de San Pablo, el autor realiza de las bienales como formas de presentación del arte: “'Cómo vivir juntos', la más política de las interrogaciones que el arte actual puede hacerse (o lisa y llanamente, la única pregunta política que importa)" "“Orfeo contra las sirenas" s/p). El interrogante habilita entonces la reflexión pero, al mismo tiempo, instaura un criterio de valor: es lo que vuelve atractiva la edición del 2006 en detrimento de las posteriores que si bien también plantean como central la relación entre arte y política lo 
hacen bajo lemas que el autor considera abstrusos. En este sentido, Mujer sin destino (2006), el primer largometraje de Rocío Fernández, se destaca por plantear "con toda su fuerza", la pregunta "capital de nuestro tiempo": “¿Qué política del vivir juntos se podría sostener?”. El valor de la película se cifra entonces en el modo en que se resuelve el planteo oponiendo a los milenarismos de moda una política de la amistad: “¿Una política de la amistad semejante alcanza para lanzarse a conquistar el mundo o para proponer un arte? Mujer sin destino parece insinuar que sí. (...) Por supuesto, a una política tan radical solo puede corresponder una estética igualmente radical" (“Alfajores marplatenses" s/p).

Ahora bien, es en el abordaje de las producciones de Manuel Puig donde esta pregunta se expande hasta generar un punto de vista que, en "Vivir juntos", le permite al ensayista singularizar su lectura de la del resto de los analistas:

No es, como muchos analistas de su obra han creído percibir, que Puig no pudiera salir de la cárcel de representaciones con las que la cultura industrial codificó todos nuestros comportamientos: es que Puig se obligó a habitar esas cárceles (y a escuchar esas voces) por solidaridad con quienes estaban, efectivamente, presos del mundo.

La literatura nunca fue para Puig un programa estético (una máquina de hacer novelas) sino, sobre todo, un dispositivo ético: la manera de analizar (postular, rechazar) formas de vida y formas de vivir juntos (...) la obra de Puig es el despliegue obsesivo y sistemático de una misma y única pregunta: ¿cómo vivir juntos? (s/p).

La apuesta se enfatiza en "La obra como exigencia de vida" (2010), artículo posterior que retoma algunos fragmentos textuales de "Vivir juntos" pero que, al mismo tiempo, en los desarrollos que suma, le otorga aún mayor peso al interrogante. Ya desde el comienzo se subraya el valor de la pregunta al asociarla a los modos de pensar lo contemporáneo: "la obra de Puig es el despliegue obsesivo y sistemático de una misma y única pregunta: ¿cómo vivir juntos? (que literariamente equivale a: ¿cómo ser contemporáneo?)" $(\mathrm{s} / \mathrm{p})^{2}$. A partir de allí, el cuestionamiento habilita en esta ocasión no solo el abordaje de una producción sino el armado de un recorrido por la obra del

\footnotetext{
El valor que se le otorga en esta superposición de interrogantes a las posibilidades de "ser contemporáneo" parece estar ligado a los desarrollos de Giorgio Agamben, autor central en el marco teórico de los ensayos de Link, en torno a las diferencias entre lo actual y lo contemporáneo. Cf. “¿Qué es lo contemporáneo?”.
} 
autor-recorrido que hace retornar literalmente pero sin marcas los desarrollos de Tiqqun en torno al problema de la comunidad: "Cuando dos cuerpos afectados, en un cierto lugar, en un cierto momento, por la misma forma de vida se encuentran (...), tienen la experiencia de un pacto objetivo, anterior a toda decisión..." ("La obra como exigencia de vida" s/p). La relación con el estereotipo, uno de los problemas centrales de la escritura de Puig, se aborda, entonces, en el vocabulario que abre la pregunta: "Multiplicidad de lo viviente"; "comunidades inconfesables"; "asunción de una forma de vida"; conversión de "la forma de vida en fuerza"; pensamiento estratégico entendido como la posibilidad de asumir una forma de vida siguiendo el incremento de su potencia. Herramientas todas que reaparecen en el intento de dar cuenta de la radicalidad del objeto que se intenta abordar. El giro que supone el enfoque marca incluso el acercamiento de Link al problema de la voz:

[Puig] hizo pasar por su escritura una sofisticada investigación del modo en que se correlacionan juegos de lenguaje y formas de vida. ¿No dice eso su obra una y otra vez, al haber renunciado a la voz propia en favor de las voces de los otros: la vida de pueblo, la vida de artista, la vida de escritor, la vida de esposa, la vida del militante y la de la marica, la del obrero y la de la psicóloga, la del desaforado sexual y la de la hermana incestuosa? ("La obra como exigencia de vida" s/p).

Pero, como señalé en la introducción, esta pregunta no solo es una herramienta para el contacto con la literatura y el arte sino que reaparece en el acercamiento a otro de los objetos favoritos de Link: las series televisivas. En estos análisis nuevamente se torna central la interrogación por las formas de lo viviente: "Qué es lo vivo y cómo salvarlo (o cómo aniquilarlo para siempre), se pregunta The Strain" ("La reentrée" s/p). En el espacio que le abren al ensayista las series televisivas, a diferencia de lo que ocurría en la evaluación de productos audiovisuales que quedaban claramente del lado del arte como La mujer sin cabeza, los enfoque milenaristas no son denostados sino que son utilizados para justificar la importancia de plantear el cuestionamiento en estos términos: la interrogación se vuelve necesaria frente a las ruinas del humanismo burgués y el abandono de los paradigmas judeo-cristianos "en la consideración de qué cosa es estar vivo". En este contexto, los finales que se formulan, como mimetizándose con aquello que ocupa la mirada, adquieren rasgos catastróficos y la pregunta queda estrechamente ligada a la imaginación en torno a las formas de supervivencia. Es a propósito de estos 
problemas que en “La reentrée (2)" se piensa explícitamente la relación entre literatura y televisión:

La literatura ha producido reflexiones memorables como la novela de Ishiguro Nunca me abandones (2005), que alcanza con delicadeza los límites mismos de lo pronunciable. Las ficciones televisivas (las series, bah) acompañan esa interrogación como pueden, con mayor o menor suceso ( $\mathrm{s} / \mathrm{p})$ [el subrayado es nuestro].

Las series quedan ubicadas, entonces, en el casillero de lo "no memorable". Sin embargo, a medida que se recorren diversas entradas de las etiquetas "Diario de un televidente" y "Formas de vida", se vuelve palpable que ese "como pueden" -que en el marco de la lectura de Puig deja de ser un término casual-adquiere una potencia mayor a la que el ensayista está dispuesto a otorgarle en esta comparación. Superior incluso a la que podría admitir según sus propios imperativos que, en muchas ocasiones, valoran las tensiones que surgen en torno a la relación con los mass media. La serie televisiva como objeto, cuando se aboca a estas interrogaciones en torno a lo viviente, no limita la imaginación del ensayista sino que la expande. Le permite ensoñarse en diversos escenarios: "Lejos de quitarle belleza, el silencio hace de Londres el perfecto monumento funerario de la especie (algo así como un British Museum de mayor escala todavía)" ("London" s/p). Y conectar así con formas del final y la supervivencia que van más allá de las posibles postulaciones teóricas sobre "el final del arte" y las reticencias morales a los milenarismos: "La pregunta que organiza la reunión de los sobrevivientes [en Being human], al comienzo, es cómo vivir juntos. Luego se verá que no hay respuesta para algo semejante y que, en todo caso, más vale preocuparse por el bien morir" ("London" $s / p$ ).

En una invectiva contra ciertos sectores del campo intelectual, Link explicita las comunidades que le interesan: "una comunidad que no puede llamarse comunismo porque no tiene límites ni ansía otra cosa que la confesión de su fracaso (no una comunidad de héroes, sino de monstruos)". ("Una especie" $\mathrm{s} / \mathrm{p}$ ). Comunidades de monstruos entonces, pero de monstruos como los de Being Human: restos de una humanidad desfalleciente pero también restos de sus estirpes monstruosas; monstruos que "están fuera de la clase (social, naturalmente) al mismo tiempo que fuera del género y de la genealogía." (“Clase media" s/p). 


\section{II.- SOÑAR EL CIELO}

Las clases comenzaron a volverse una pieza fundamental en el aparato teórico-crítico desarrollado por Link en Cómo se lee y otras intervenciones críticas (2003) a propósito de la reflexión en torno a la relación entre arte, cultura y género. Pero es en el libro que lleva el concepto en su título (Clases. Literatura y disidencia) donde las mismas desempeñan un papel protagónico desde el comienzo y son utilizadas para definir lo que se quiere hacer. En el "Umbral" de dicho libro, Link explicita el objetivo que reúne los textos que lo componen: leer lo que "hay de resistencia a la captura, al disciplinamiento, a la normalización y al exterminio" (19) en ciertos textos literarios emblemáticos del siglo XX. Es decir, lo que se resiste a la clase. Esta búsqueda habilita una autofiguración: el ensayista, el yo, se define como aquel al que "le gusta pensar" el "arte experimental", esas "voces que nos interpelan, todavía, porque sostienen nuestro mismo sueño: sueñan el cielo, miran el cielo, hacen el cielo" (19). Sin embargo, en una nota al pie que había aparecido solo dos páginas antes -a propósito, también, del tópico del deseo del cielo pero en una serie que, en ese caso, conectaba a Borges y a John Cage con San Sebastián-se había sostenido lo siguiente: "Si he suministrado dos ejemplos no literarios (San Sebastián, Internet) ha sido deliberadamente: nadie piense que sostenemos una hipótesis autonomizante sobre la literatura" (17). Podríamos, entonces, en el marco de la reflexión sobre las comunidades monstruosas (las únicas verdaderas comunidades), interrogarnos: ¿Cómo conviven ambas autofiguraciones y los objetos que valoran? ¿Cómo viven juntos el gusto (casi obvio) por pensar el arte experimental, en función del imperativo que plantea el deber de dar cuenta de las formas de resistencia, y la necesidad de explicitar que no se sostiene una hipótesis autonomizante de la literatura? ${ }^{3}$

"Pop" permite realizar un primer acercamiento al modo en que debería leerse la relación entre ambas posibilidades. Allí, Link sostiene que "[t]enemos

\footnotetext{
Sabemos que el arte experimental, atrapado por la institución, se caracteriza necesariamente como autónomo; sin embargo, como potencia de invención, potencia que implica justamente la resistencia a la clase, la categoría "autonomía" le es indiferente, lo que vuelve innecesaria y, por lo tanto, marcada la explicitación de Link. Para plantear los interrogantes de este modo sigo la interrogación de Alberto Giordano en torno a los pares literatura/cultura y ética/moral en Roland Barthes. Literatura y poder. Sobre el lugar que ocupa el concepto de autonomía en los ensayos de Link, cf. Gasparri "Las aventura (in)formales de Linkillo".
} 
pues, un universo, el arte, la literatura, y otro universo, la cultura, en relación con los cuales no parecería, en principio, haber identidades totales pero, tampoco, desemejanzas absolutas" (27). La relación entre ambos universos no es, entonces, armoniosa, sino que supone una batalla, siendo la década del 60 -el período sobre el que vuelve obsesivamente el ensayista y que capta su interés de diferentes formas desde La chancha con cadenas- su momento más dramático. Es esa batalla la que, debido a la ruptura de los límites y a la fusión de ambas esferas en beneficio de la segunda, nos habría dejado sin arte. Falta ante la cual se puede esgrimir una sola estrategia, la simulación: "Toda una poética de la simulación será lo que nos permita seguir pensando que el arte existe" (33). La apelación al final que supuso el pop (y su consecuente "desorden de la clasificación" que obliga a una apertura radical y vuelve inválidos patrones anteriores del juicio estético como los que permitían cualificar y, por lo tanto, definir el arte de vanguardia o el modernismo histórico) y, simultáneamente, a la estrategia de simulación (que nos permite seguir ensoñándonos con el cielo del arte) resolvería en una primera instancia, aunque no sin conflicto, la convivialidad entre los dos modos de leer que abrían las autofiguraciones que se delineaban en "Umbral" . Resolución que se prolonga en la forma en que se suceden los textos: los ensayos son presentados juntos y bajo la égida de un prólogo, pero, al mismo tiempo, el punto de vista y el objeto de interés pueden variar de uno a otro sin volver imperativa la pregunta por dicho cambio, ni por los modos de convivencia (pudiéndose también extender esto a las múltiples profesiones con las que se regodea Link en su autofiguración). Sin embargo, hay momentos en que esa relación aparece como verdadero interrogante, sobrepasando el lugar seguro que parecería brindar la "simulación" o la necesidad de borramiento de los límites convertida en valor. Momentos en que las preguntas que se plantean a partir de la relación arte y vida retornan con una verdadera urgencia, con la urgencia que supone la necesidad de interrogarse por los modos de vivir juntos:

Si el arte, por todo lo anterior, deja de concebirse como una esfera separada y autónoma de prácticas, al mismo tiempo entra en continuidad (forma un continuo) con la experiencia vital, política y cultural. Es, tal vez, el mayor momento de peligro del arte: derribada esa muralla,

\footnotetext{
Para los diferentes matices en el uso de "convivialidad" y "convivencia" cf. Barthes, Cómo vivir juntos.
} 
¿cómo detener por un lado, el derrame de lo estético? ¿Cómo sostener, por el otro, los antiguos órdenes culturales? Quena, charango y sikus para tocar una fuga de Bach (29).

En este sentido, cuando hacia el final del ensayo Link se explaya sobre la posibilidad de la existencia de una literatura pop, la elección del best seller como punto de vista desde donde abordar la cuestión pone en jaque cualquier solución basada en decisiones previas (Tiqqun s/p). Al intentar definir ese tipo de producción, el autor cae, como al pasar, en un uso particular de las comillas: "ese tipo de producción «literaria» de la cual es muy fácil decir que no puede evaluarse en términos artísticos aunque resulte más difícil demostrarlo" (46). Para reflexionar sobre esta dificultad el ensayista se desvía, paso seguido, a las conexiones formales, un problema mucho más fácil de abordar, pero que deja al lector suspendido en la imposibilidad de determinar claramente a qué se debe la utilización de esa marca: ¿el adjetivo literario ya no es válido como cualificación?; ¿el best seller no debería ser calificado mediante ese adjetivo?; ¿de qué manera se valora "ese tipo de producción” en el contexto actual? A partir de allí la pregunta por la existencia de la literatura pop (una pregunta conflictiva de por sí: ¿se puede preguntar sobre algo que se define por escapar a las clases si existe calificado por un adjetivo que lo captura dentro de una corriente? ¿no sería "más correcto" según los propios imperativos contactar con la imposibilidad de existencia?) y la decisión metodológica de apelar al best seller genera la necesidad de moverse entre esferas diversas: fenómeno económico/función estética, category fiction/Literary fiction, mercado/ escuela, público llano/público culto 5 . Una nueva apelación a la figura de Puig, cifrando en ella la capacidad de estar "en los dos lados al mismo tiempo", se presenta como una primera opción para pensar posibles modos de relación. Pero, no conforme con esto, párrafo seguido, Link coloca junto a Puig a otros tres escritores que esgrimirían la misma astucia: Tolkien, Humberto

$5 \quad$ Cuando en "Ley" Link se ocupa de Kafka plantea justamente que lo que diferencia a este autor de sus contemporáneos es no haberse inscripto en los "géneros como clases". Esta impugnación de las clases es fundamental para pensar la paradoja de la "literatura pop", ya que el contra ejemplo a la "experiencia radical de ascesis" kafkiana es el viraje de Werfel justamente hacia una corriente, hacia el expresionismo. Es en este mismo ensayo en donde Link insiste, además, en presentar los axiomas como modos de reterritorialización propios del capitalismo. En este sentido, si bien Link cuestiona agudamente la transgresión como modo privilegiado de relación con las clases, podríamos pensar que en la valoración de la ascesis kafkiana sus propios axiomas no se ponen en juego con la misma radicalidad. 
Eco y Truman Capote. La convivencia de los objetos obliga a interrogarse por las distancias: ¿cómo se cualifica la diferencia entre Puig (ese autor del cual el ensayista dice no poder hartarse) y los otros tres escritores con los que se arma la serie?; ¿se la anula borrando la diferencia entre esferas (como de hecho se hace a párrafo seguido)?; ¿se descarta el problema sacando a la literatura de cualquier adjetivación (dejándola en un cielo para contemplar)? En los momentos más interesantes de los ensayos de Link las respuestas quedan en suspenso, como si el intento de comunidad de los puntos de vista fuera realmente eso, un intento monstruoso y no simplemente el camino hacia una comunidad como comunión (Nancy, La comunidad inoperante). La introducción, en el último párrafo, de la categoría de "lo viviente", que subvierte una afirmación inmediatamente anterior en la cual se apelaba a "la literatura" como la salida a todos los problemas, parece condensar la radicalidad y la urgencia del intento:

Y cuando nos parece que es solo la voz de la cultura la que suena y resuena como un loco murmullo en los textos, en verdad nos equivocamos porque está allí, antes que nada, la voz de lo viviente sometida a políticas contradictorias que nos involucran (o reclaman que nos involucremos). Nunca como ahora, cuando las jerarquías se debilitan por el lugar menos previsto, la experiencia de leer (un texto, una película, un gesto) se nos revela con toda su fuerza política. En ella se apuesta al futuro del mundo (50).

Si "Pop" delinea así los imperativos para el abordaje al mismo tiempo que deja entrever los desvíos del ensayista, "Cuerpo" nos permite observar estos movimientos en relación directa con la interrogación sobre las formas de vida, cuestionamiento estrechamente asociado a la pregunta por cómo vivir juntos. Y allí la televisión vuelve a jugar un rol extraño. El artículo parte de un poema de Ariel Schettini para, posteriormente, dar lugar a un análisis de las reflexiones en torno a la biopolítica de Michel Foucault. El ensayista se detiene minuciosamente en la implicancias teóricas del concepto, siendo las clases, la posibilidad de cualificación y los umbrales herramientas que provee el objeto que se confronta, al mismo tiempo que elementos que posibilitan el acercamiento. En este contexto se sostiene lo siguiente: "No hay que preguntarle solo a los médicos qué piensan y qué saben de la vida y de la muerte. También hay que preguntárselo a los guionistas de televisión, a los filósofos, a los poetas, a cualquier persona" (125). Paso seguido se introduce un nuevo poema de Schettini, en el cual, según el ensayista, las 
voces resuenan "en (y contra)" las voces de las clasificaciones, "con (y contra) el pensamiento encarnado del arte" (129). Sin duda el poema de Schettini, luego de esta descripción, no es simplemente un documento de esas voces a las que se decía que había que interrogar. Sin duda también no todas las voces son equivalentes. Por eso, tal vez, la referencia en el marco de estas interrogaciones a la serie televisiva $E R$ se hace en nota al pie. Sin embargo dicha nota, que nos muestra cómo la discusión sobre la vida se ha convertido en entretenimiento, culmina con una interrogación que interpela tanto como lo hace la descripción de las voces de Schetinni: "Uno de los más recientes debates que la serie introdujo involucraba dos puntos de vista antagónicos a propósito del trasplante de órganos entre personas portadoras del virus HIV ¿Debemos asistir a ese debate como quien asiste a un espectáculo?” (128) ¿Cuál es el referente de "espectáculo"? ¿La serie televisiva? Pero si esta habilita plantear así los interrogantes ¿no convendrían, según los propios imperativos, sacarla de la clase? ${ }^{6}$.

Promediando "Beat", intentando justamente cualificar a Naked lunch en contraste con Lolita, Link sostiene lo siguiente:

El debate entre quienes hacen literatura y quienes hacen estudios culturales, en el fondo, está regulado por la densidad que se le otorga al contexto en el análisis de una obra cualquiera. Los dos polos de la crítica son el análisis cultural (en relación con el cual el texto se satura de sentido en relación con el contexto) y la deconstrucción (que tiende a prescindir totalmente de él). En el medio, opciones menos radicales y, también, más adecuadas a los fines de la pedagogía (58).

Es evidente que si bien este imperativo crítico puede funcionar como punto de partida, hay ciertos momentos en que el movimiento del ensayo no se puede entender solo en función de estos parámetros. Momentos en que esas opciones que el ensayista califica como menos radicales parecen, en cambio, poner en entredicho las definiciones lineales en torno a lo que se hace, convirtiéndose en verdaderos umbrales. Umbrales en los que el ensayista -habilitado por los imperativos que delinean su autofiguración-interroga los límites, poniendo en

\footnotetext{
Algo similar ocurre cuando se relacionan televisión y teatro en "Absurdo". La serie y la sitcom, formatos que no pertenecen al arte pero que se interrogan con la misma pasión, son centrales también allí para pensar las posibilidades del "vivir juntos" de los intereses. He trabajado más detenidamente sobre este ensayo en "Ensayos sobre la televisión: Daniel Link".
} 
contacto objetos que su mismo punto de vista presenta como diversos, pero en torno a los cuales, sin anular dicha singularidad, se generan interrogantes con similar potencia de interpelación; interpelación que desarma las explicaciones plausibles para dicha convivencia, suspendiendo cualquier tipo de decisión previa, incluso aquella que la propia autofiguración propone.

\section{III.- SIRENAS Y FANTASMAS}

En su "Umbral", Clases en ningún momento explicitaba que la resistencia a la normalización podía convertirse en una nueva clase que desembocara o bien en la homogeneización como imperativo o bien en el aislamiento finalmente esteticista del arte experimental. Fantasmas, en cambio, le da un lugar central al problema desde el íncipit. Y lo hace justamente en el marco de la reflexión sobre los alcances y limitaciones del libro anterior:

Clases, en su obsesión por los dispositivos de clasificación y sus efectos colaterales (la normalización, la determinación del Ser, en todo caso), presuponía el problema de las cualidades, porque en algún sentido clases y atributos (clasificación y cualificación) bailan la misma ronda tomados de la mano (9).

A pesar del énfasis del ensayista en la continuidad, lo cierto es que la posibilidad de explicitar eso que se dice estaba presupuesto modifica el punto de vista. Los imperativos que se formulan en esta ocasión a partir de la relación entre clasificación y cualificación habilitan un horizonte de acción mucho más amplio: Link se propone en esta ocasión no solo "leer en ciertos textos más o menos emblemáticos de la literatura del siglo pasado todo lo que hay de resistencia a la captura, al disciplinamiento..." (Clases 19), sino fundamentalmente examinar los umbrales y las potencias, trazar mapas de imaginarios, definir fantasmas. Y este desplazamiento afecta directamente a la figura del monstruo que, como hemos visto, es central en la ensayística del autor y en su planteo del problema de las comunidades. El monstruo sigue siendo fundamental para presentar el entre-lugar que ocupan las sirenas, esos seres mitológicos en torno a los cuales se desarrolla la argumentación en "Umbral": “... las sirenas no son naturales ni tampoco sociales (...) No están ni en lo Real (lo Natural) ni en lo Imaginario (los delirios narcisistas de identificación) ni en lo Simbólico (la estructura social entendida como sistema de clasificación o como dispositivo de interpelación): son monstruos" 
(26). Sin embargo, el movimiento desclasificador que, en primera instancia, supone lo monstruoso parece no bastar; paso seguido, mediante una nota al pie, las sirenas quedan ligadas a los fantasmas y, por lo tanto, a la necesidad de calificar: "Quiero decir desclasificadas aún cuando no estén descalificadas, o precisamente por eso. No hay fantasma descalificado (aun cuando todo fantasma sea, por principio, un desclasificado) y para que haya fantasma debe haber calificación: las sirenas son, como se verá (...) 'esas poderosas cantantes" "(26).

En este contexto, los objetos específicos de los cuales se van a ocupar los ensayos quedan definidos desde la obviedad: "Como no podía ser de otro modo, además de textos literarios, a lo largo del libro se proponen lecturas de "imágenes" (películas y programas de televisión, preponderantemente, $\mathbf{y}$ con total prescindencia de la institución artística)" (11) [el destacado es nuestro]. En este sentido, si, por ejemplo, los ensayos que se incluyen en la tercera parte giran en torno al enunciado fantasmático "hay guerra", el mismo se presenta, según nos lo aclara coherentemente Link, "a veces, en contextos de intervención más bien graves y otras, en relación con trivialidades" (11). Ahora bien, si los objetos parecen convivir pacíficamente en la escritura del ensayista en función de ciertos objetivos (decisiones) previos, la definición del modo de examen es menos precisa y más compleja. Ese modo, se nos dice, no puede ser el del esteticismo que separa y jerarquiza, asigna y designa propiedad. Debe poder, en cambio, dar cuenta "de un umbral de seducción" no de un "límite de comprensión"; pero sin confundir fantasmagoría con cultura, seducción con normalización. Confusión, y aquí retorna el problema planteado en Clases, que se halla en la base de "la pretendida autonomía del arte”. ¿Cómo generar, entonces, contacto con la seducción (de la presencia del otro) sin obligar a comprender(lo)?

Tal vez es debido a esta complejidad que el primer apartado, casi desoyendo las advertencias barthesianas, se denomina "Método"7. Como su título lo indica, la sección tiene como objetivo delinear los conceptos para dar lugar al

Justamente en Cómo vivir juntos Barthes sostiene lo siguiente: "Método. Supone "una buena voluntad del pensador", "una decisión premeditada" (...) Idea de camino recto (que quiere ir hacia un objetivo). Ahora bien, paradójicamente, el camino recto designa los lugares adonde en realidad el sujeto no quiere ir: fetichiza el objetivo como lugar y, por ello, descarta los demás lugares, el método se pone al servicio de una generalidad, de una "moralidad" (ecuación kierkegaardiana). El sujeto, por ejemplo, abdica de lo que no conoce de sí mismo, lo irreductible de sí, su fuerza ( $\sin$ hablar de su inconsciente)"(45). 
abordaje; pero, lejos del "camino recto", en ella la multiplicidad de formatos y los diferentes lugares para la propia voz que estos habilitan generan un "trazado excéntrico". Allí, Link examina el concepto de imaginario no solo mediante diversos ensayos y reseñas (que de hecho se presentan al final del apartado) sino también a través de "cartas". El vivir juntos de las voces otras (efectivas o supuestas) queda así en primer plano, volviendo esta sección central en función del modo de acercamiento que he desarrollado. Sin duda, dada la fortaleza del yo que articula la autofiguración en ambos "Umbral(es)", esta elección podría no ser más que un simulacro para instaurar una idea de proceso y heterogeneidad que escondería en su envés la comunión bajo la supremacía de una voz única ${ }^{8}$. En este sentido, cuando se utiliza al primer destinatario para sostener la falta de atención de la que ha sido objeto la imaginación, no se puede dejar de observar que dicha aserción presupone la originalidad del punto de vista del que escribe y, por lo tanto, la escucha del otro parece, más allá de si es real o ficticia, impostada.

Sin embargo, hay momentos en que la multiplicidad de voces parece estar en la base de la posibilidad de pervivencia y percepción de énfasis diferentes (escucha de las fuerzas/escucha de las diferencias (Barthes, Cómo vivir juntos 46)). Así, a pesar de que en el prólogo el problema de la clasificación parecía haberse resuelto con la figura de la ronda y la opción por los fantasmas y los umbrales, en algunas de las cartas el autor no puede dejar de volver sobre el poder encarcelatorio y de captura de la cultura. Esto conlleva casi inevitablemente la definición del arte mediante una lógica opositiva: "entre fantasmagoría (como potencia) y la cultura (como dispositivo) la relación es de abismo" (51); "Lo imaginario en su estado más puro nos arrastra a una versión de la literatura como el arte de lo no construido, en vez de la opción (mucho más banal) de la literatura como arte de lo preconstruido" (42). Es decir, al mismo tiempo que, en la respuesta a Estela, se apela, a través de la referencia a Deleuze y a Blanchot, a lo indeterminado como forma de resolver

\footnotetext{
En este sentido, Link sostiene en el último "Umbral": "Algunos de los fragmentos que se leen en "Cartas" (en la primera parte) fueron enviados como respuesta a los alumnos que cursaban un seminario de posgrado online (...) Otros fueron escritos de acuerdo con el mismo modelo genérico, porque me interesaba restituir la carta (que ya no cultivamos) a un lugar en el que alguna vez cumplió un papel decisivo" (438) ¿Por qué "develar el truco"?; la incertidumbre con respecto al origen ies mayor cuando no se realizan explicitaciones o cuando se introduce esta aclaración que pone en primer plano un límite de la clasificación (la "aclaración del carácter ficcional" (Fantasmas 81)) que en otros momentos ha sido rechazado?
} 
la necesidad de cualificar sin clasificar (y que se hace oír la voz de Antelo contra el "retorno de las formas autonomistas de pensar la cultura") se sigue hablando, para corresponder a las inquietudes de Beatriz, de "la literatura como arte" [el destacado es mío]. El fragmentarismo de las cartas -que acorta la distancia que separa, por ejemplo, un ensayo de otro pero sin anularla totalmente; que provoca el contacto que vuelve perceptible la singularidad manteniendo al mismo tiempo la soberanía en el reparto- permite y vuelve observable la convivencia, no de ideas contradictorias, pero sí de intentos ligeramente diferentes. El "y" (Estela y Beatriz), tal como lo sostiene Nancy, se libra así del valor de yuxtaposición para adquirir el de exposición ( $L a$ comunidad inoperante 40). La determinación indefinida podría, sobre todo si se apela a ella en el contexto de un "método", convertirse en una "proposición asertiva"; el hecho de que en otros momentos de ese conjunto de cartas el autor se arriesgue a la definición de otros axiomas (sobre todo al intentar decidir qué es la literatura) previene de esa posibilidad y al mismo tiempo abre el juego en torno a ella.

$\mathrm{Si}$, entonces, se sostiene como proposición que la indagación del imaginario no supone necesariamente al arte ("No es el arte, por lo tanto, con lo que nos toparemos en una indagación de lo imaginario, sino con aquello que no lo es: figuras, fantasmas, unidades de lo imaginario como fuerzas, potencias o movimientos que están más allá o más acá de lo artístico (el plano de composición)...". (70-71)), las insistentes definiciones de literatura que vuelven en las cartas (y por qué no también el hecho de que esta rama del arte sea el referente principal de los ejemplos) no pueden sino quedar, paradójicamente, del lado del gusto del ensayista. Digo paradójicamente porque justamente el gusto para Link supone, tal como lo sostiene al

9 En Lo neutro, Barthes sostiene: "La restricción de la aserción pasa de la lengua al discurso, pues el discurso está hecho de proposiciones que son naturalmente asertivas. Lo cual hace que para preservar el discurso de la afirmación, para matizarlo (hacia la negación, la duda, la interrogación, la suspensión), sea necesario batallar sin cesar con la lengua, materia prima, "ley" del discurso" (94). En este contexto, la apelación a lo neutro, central para Link para pensar los modos de cualificación, es siempre paradojal: "He dicho: el discurso debe "batallar" con la lengua, cuando quiere deshacer su asertividad natural. En efecto, se trata sin cesar de una lucha, de una prueba de fuerzas: se encuentra aquí la paradoja de lo Neutro: pensamiento y práctica del no-conflicto, está constreñido a la aserción, al conflicto, para hacerse oír utiliza el concepto justamente como para pensar las formas de cualificación que suspenden la presuposición de existencia" (94). 
responderle a Ignacio, procesos de identificación (algo que sus definiciones de literatura intentan evadir):

En el "me gusta/no me gusta" (no me gustan las películas con monjas, por ejemplo (...)) se cifra toda la máquina binaria de las identificaciones. No hay necesariamente que abominar de esos procesos de identificación sino que hay que ser capaz de notarlos (...) No proscribamos la relación con lo Mismo, pero sepamos que esa relación con lo Mismo está puesta bajo la vigilancia necesaria de lo Otro (64).

Si no es obligatorio abominar de esos procesos de identificación pero sí es necesario ponerlos bajo la vigilancia de lo Otro, ¿qué funciona como Otro (en tanto "línea de fuga de la identidad") en estas cartas/ensayos de "Método"? ¿el arte? ¿los fantasmas más allá de lo artístico? La multiplicidad de énfasis (los diferentes interlocutores) permiten (obligan a) mantener esto en el desarrollo del método de Link como interrogante.

En el entorno que constituyen las cartas, la referencia explícita al problema de la comunidad se presenta como un eje importante sobre el que en ciertos momentos se detienen las reflexiones: se lo menciona para pensar la negación no destructora y la diferencia mínima ligada directamente con el pop, columna vertebral de la ensayística de Link ("¿cuál es la diferencia mínima que me separa del prójimo (Pierre, digamos)?, ¿y cómo se articula la serie de diferencias con la noción de comunidad?" (63)); y reaparece el intentar pensar el modo en que se trabaja sobre/en el imaginario ligándolo a la vida (“¿cómo hacemos para vivir en esas figuras, entre ellas, con ellas?" (72)). Sin embargo, es en los fragmentos que se reúnen bajo el título de "Yo" donde la pregunta realmente posibilita el desarrollo de una de las proposiciones más interesantes de esta compilación: la que sostiene que la insistencia en el yo (en la literatura actual) obedece a una voracidad por lo concreto, a "la necesidad de inscribir el propio cuerpo en relación con todo lo existente" (85). En este apartado se juega nuevamente un intento de cualificación sin clasificación a través del formato de los textos que se incluyen: se conjugan fragmentos de ensayos de diversa índole y "ficciones" en función del mismo interrogante, como si todos vehiculizaran la misma potencia de interpelación, pero, lejos de homogeneizarlos, la cualificación pervive en la separación que crean los asteriscos y en la utilización de itálicas -y también en la nota al pie que aclara la procedencia y el carácter de los textos, tal vez traicionando y volviendo a clasificar, pero también generando por esto mismo un movimiento más intenso. En este contexto, la fórmula "inscribir el propio cuerpo en relación con todo 
lo existente" se vuelve posible gracias a la presentación de la literatura como una comunidad (otra vez, paradójicamente, la definición) ${ }^{10}$ :

La literatura, así, no sería tanto algo que se vuelca (más, o menos) hacia lo íntimo, sino un éxtimo, la extimidad en su forma más aguda o más disparatada, y eso por su propia lógica de inscripción y aun (si se quiere) por su presupuesto destino: una comunidad de quienes han declinado la propiedad del "yo" (83)

Ahora bien, ¿solo en torno a la literatura adviene la posibilidad de este tipo de comunidad? No, obviamente no. Hay otra comunidad que a primera vista podría resultar externa al "arte" pero que es presentada con similares características, la de los comentadores de blogs:

¿Por qué comentar lo que otro escribe, como sucede en esas deshilvanadas producciones novelescas llamadas blogs (no lo que hace la crítica, sino comentarlo, lato sensu)? Volvemos al punto de partida: se trata de inscribir el propio cuerpo en relación con todo lo que existe (...) Como si uno pudiera engancharse en un pormenor determinado (...) para continuar el relato (la argumentación, el poema) en una dirección imprevista, en una comunidad (imposible) de experimentantes (85).

"Comunidad de quienes han declinado la propiedad del "yo", "Comunidad (imposible) de experimentantes": idiorritmia entre universos que se acercan y a la vez mantienen y experimentan en torno a una ética de las distancias (cf. Barthes, Cómo vivir juntos).

El otro matiz que abre la pregunta por cómo vivir juntos, el asociado a la reproducción, aparece en el último de los textos del apartado: “2015”. Y lo hace no a propósito de la literatura sino del cine. Al resumir las características positivas de Eli, Eli, lamma sabacthani? de Shinji Aoyama, uno de los objetos del ensayo, Link sostiene lo siguiente:

[la postulación de un universo futuro conectado con una cultura glocal] vuelve aún más extraño, fascinante e hipnótico un film que,

10 La justificación teórica se va a consignar solo hacia el final: lo que le "importa" al ensayista, siguiendo los desarrollos de Jean-Luc Nancy, no es el "ego sum" sino el "egocum". Punto de partida que realmente supone un aporte a lo que se ha discutido sobre el giro autobiográfico de la literatura argentina actual. Sobre este problema cf. Giordano, El giro autobiográfico de la literatura argentina actual. 
al mismo tiempo, se descoloca del modelo del relato clásico para salirse de la ciencia ficción, postula la música órfica del mañana y se interroga sobre la continuidad de lo viviente (¿cómo y para qué hemos sido concebidos?) (150).

Este modo de valoración obedece a la manera en que se ha nombrado la producción del cineasta: arte. Pero éste no ha sido el único objeto del ensayo. Link comienza "2015" listando una serie de películas claramente pertenecientes al circuito comercial: Día de la independencia, El día después de mañana, La guerra de los mundos, Armageddon. A propósito de ellas, lo único que puede hacer es "verificar" la captación de ciertas unidades de la imaginación de la catástrofe y vuelve así necesariamente a la oposición con la cultura. Pero luego aparece The happening, fácil de asociar al mismo circuito, pero que en el desarrollo del ensayo va a mediar entre el arte y la verificación, y a propósito de la cual Link confiesa "dejarse arrastrar". En la explicación de lo que surge debido a ese dejarse llevar se crean, necesariamente, escalas de valor, similares a las que se propusieron a propósito del film de Aoyama (la potencia del nihilismo, la impresión hasta el desasosiego que generan ciertas imágenes, la falta de argumentaciones, de desesperación, de posibilidades de salvación se presentan obviamente como positivas). Pero hay un momento en que las mismas quedan suspendidas en una utilización de las comillas y de la itálica que vuelve a ser ambigua: "[The happening] no ha sido vista como una "gran" película ¿cómo podría hacerse una "gran" película, una película divertida, inolvidable, con semejante tema?" (147). El modo en que se ha abordado el primer listado obligaría a hacer énfasis en "el semejante tema" y las imposibilidades que supone, por lo que los logros tendrían siempre ese límite. Pero si seguimos las afirmaciones de Link a propósito de la película de Aoyama, la proposición podría volverse irónica y The happening podría convertirse en una gran película. Es, entonces, el vivir juntos, que se explicita solo al final pero que marca el ritmo de todo el ensayo, el que obliga nuevamente a sostener los condicionales.

\section{IV.- COMUNIDADES}

En el camino que he armado a través de la ensayística de Daniel Link pueden observarse los desarrollos y posiciones singulares que conlleva la puesta en el centro de la pregunta por cómo vivir juntos al mismo tiempo que la pervivencia 
de los problemas que ésta habilita más allá sus apariciones explícitas. El choque de los intereses y de los imperativos con las efectuaciones y la multiplicidad de objetos, las coaliciones que el ensayista expone (y a las que se expone, cuando no se resguarda en la moral de lo "productivo" de la tensión) hacen que destruyendo las clasificaciones, e incluso desarmando su lógica binaria, pervivan en la escritura las cualidades. Pero que pervivan fuera de cualquier posibilidad de constituir un todo orgánico, mejor dicho, una comunidad (una obra) como comunión (cf. Nancy, La comunidad inoperante). Los extremos a los que podrían llevar la pérdida o el exceso de distancia se tocan. Por un lado, la multiplicación de intereses, el borrado de los límites y la necesidad de sostener una hipótesis no autonomizante y no esteticista de la literatura, consecuencia directa del imperativo de desclasificación, al mismo tiempo que obliga al contacto podría suponer la caída en una homogeneización que anulara la comparecencia. Por otro, la conversión en valor de esa apertura y de la tensión que supone podría terminar siendo escatología y no cualificación, distanciando excesivamente los objetos que lo logran de aquellos que no. El juego entre estos límites habilita un umbral en el que el gusto por formular imperativos, normativas y axiologías y el saber que le dice que hay que resistirse y las formas de esa resistencia y las concesiones al gusto intentan un estar juntos monstruoso que impulsa el ensayo de la escritura de Daniel Link.

\section{BIBLIOGRAFÍA}

Agamben, Giorgio. “¿Qué es lo contemporáneo?”. Otra parte 20 (2010): 77-80.

Barthes, Roland. Cómo vivir juntos: simulaciones novelescas de algunos espacios cotidianos. Prólogo Alan Pauls. Buenos Aires: Siglo XXI Editores Argentina, 2003.

Lo neutro. México: Siglo XXI Editores, 2004.

Catalin, Mariana. "Ensayos sobre la televisión: Daniel Link". Cuadernos del Centro de Estudios en Diseño y Comunicación, en prensa.

Nancy, Jean-Luc. La comunidad inoperante. Santiago de Chile: LOM Ediciones/Universidad ARCIS, 2010.

Gasparri, Javier. "Las aventuras (in)formales de Linkillo La realidad como invención”. Comp. Sandra Contreras. Realismos, cuestiones críticas. Cuadernos de seminario 2. Rosario: CELA/Humanidades y Artes Ediciones, 2013. 179-208.

Giordano, Alberto. Roland Barthes. Literatura y poder. Rosario: Beatriz Viterbo, 1995. El giro autobiográfico de la literatura argentina actual. Buenos Aires: Mansalva, 20.

Link, Daniel, comp. El juego de los cautos. Literatura policial: de Edgar A. Poe a P. D. James. Buenos Aires: La marca, 1992. 
Escalera al cielo. Utopía y ciencia ficción. Buenos Aires: La marca, 1994.

Link, Daniel. La chancha con cadenas Doce ensayos de literatura argentina. Buenos Aires: Del eclipse, 1994.

Cómo se lee y otras intervenciones críticas. Buenos Aires: Norma, 2003.

Clases. Literatura y disidencia. Buenos Aires: Norma, 2005.

Leyenda. Literatura argentina: cuatro cortes. Buenos Aires: Entropía, 2006.

“Alfajores marplatenses". Linkillo.blogspot.com. 11 de marzo de 2006. http:// linkillo.blogspot.com.ar/2006/03/alfajores-marplatenses_11.html

Fantasmas. Imaginación y sociedad. Buenos Aires: Eterna Cadencia, 2009.

"Una especie de Folies-Bergère". Linkillo.blogspot.com. 4 de marzo de 2009. http:// linkillo.blogspot.com.ar/2009/03/una-especie-de-foliesbergere.html

“Clase media”. Linkillo.blogspot.com. 17 de abril de 2010. http://linkillo.blogspot. com.ar/2010/04/clase-media.html

"Vivir juntos". Linkillo.blogspot.com. 29 de mayo de 2009 http://linkillo.blogspot. com.ar/2009/05/vivir-juntos.html

"La obra como exigencia de vida". Linkillo.blogspot.com. 24 de julio de 2010. http://linkillo.blogspot.com.ar/2010/07/la-obra-como-exigencia-de-vida.html

“Orfeo contra las sirenas". Linkillo.blogspot.com. 17 de octubre de 2010. http:// linkillo.blogspot.com.ar/2010/10/orfeo-contra-las-sirenas.html

“London, London". Linkillo.blogspot.com. 21 de diciembre de 2010. http://linkillo. blogspot.com.ar/2010/12/london-london.html

Textos de ocasión. Buenos Aires: El cuenco del plata, 2012.

“La reentrée (2)". Linkillo.blogspot.com. 1 de agosto de 2014. http://linkillo.blogspot. com.ar/2014/08/la-reentree-2.html

Tiqqun. "Introducción a la guerra civil”. Tiqqun 2. Marzo 2013. http://tiqqunim.blogspot.com. ar/2013/03/introduccion-la-guerra-civil.html 